\title{
Stability analysis of an open pit slope in a chromite mine
}

\author{
Sandi Kumar Reddy and A Rajan Babu \\ National Institute of Rock Mechanics \\ Kolar Gold Fields, Karnataka, India \\ kumarsandireddy@gmail.co
}

\begin{abstract}
In this paper the stability analysis of an open pit slope of chromite mine in Odisha state, India has been evaluated with a present working depth of $147 \mathrm{~m}$ with 280 overall slope angle to deepening the pit to $182 \mathrm{~m}$ under critical geometrical conditions like limitation of area, and having two active internal dumps with a distance of $25 \mathrm{~m}$ from pit in north and south directions. The mine having 19 benches with a height and width of $8 \mathrm{~m}$ each, and the bench angle is less than 800 from horizontal. Open pit slope stability analysis has been performed using FLAC/SLOPE of numerical modeling technique. Thus by studying the factor of safety, the stability analysis of pit slope has been evaluated and suggestions based on the geotechnical studies and numerical analysis has been presented.
\end{abstract}

Keywords_Slope design; Open pit mining; Numerical analysis

\section{I.INTRODUCTION}

The geotechnical study and slope design was conducted of an open pit chromite mine (470 m long, $420 \mathrm{~m}$ wide) situated in Odisha state, India. The width of the ore body ranges from $25 \mathrm{~m}$ to $30 \mathrm{~m}$ and $420 \mathrm{~m}$ long. The ore body is striking towards north east with an average dip of 800 due east. The grade ranges from 10 to $40 \% \mathrm{Cr} 2 \mathrm{O} 3$.

The mine comprises of a chrome mineralization ore body hosted in the Pre-Cambrian age Sukinda ultramafic complex. The chromite ore in this area is highly friable in nature. The main lithological units in this area are limonite and serpentinite.

The mine is fully mechanized. Mine development and production of ore is done with the help of excavator and dumper combination. There are 19 benches in the mine. Average bench height and width is $8 \mathrm{~m}$, and the bench angle less than 800 from horizontal. Currently, the pit bottom is at $147 \mathrm{~m}$ with 280 overall slope angle and having two active internal dumps with a distance of $25 \mathrm{~m}$ from pit in north and south directions (Figs. $1 \& 2$ ). Since the mineralized body is small and steeply dipping need to deepen the pit from present depth of $147 \mathrm{~m}$ to $182 \mathrm{~m}$. Therefore, the mine management sought the study for an optimum slope design of the open pit.

\section{II.GEOTECHNICAL STUDY}

A number of samples of the material forming the benches were collected from different locations and different depths of the developed open pit. The main lithological unit in the mine is limonite and serpentinite material. As the material was soft, it was treated like a soil, and soil testing procedures were adopted to determine its physico-mechanical properties in NIRM laboratory.

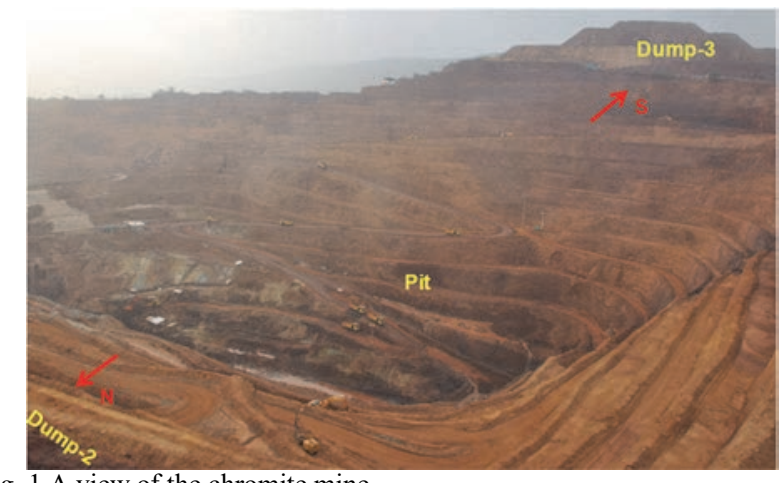

Fig. $1 \mathrm{~A}$ view of the chromite mine

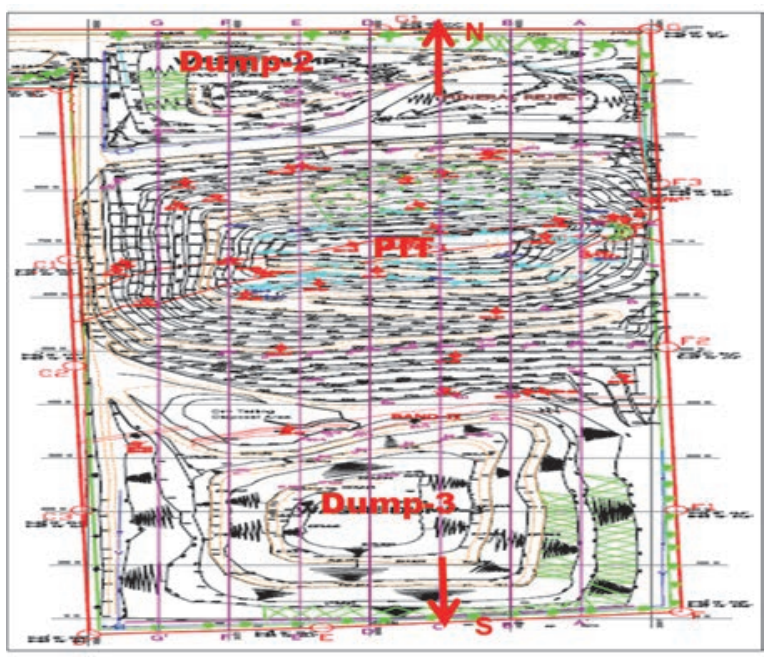

Fig. 2 Plan view of the chromite mine

Bulk density tests are conducted in the field by core cutter and hammer, and remaining tests like permeability, particle size distribution, porosity, moisture content and direct shear for shear properties (cohesion and angle of internal friction) conducted in NIRM laboratory (Table 1).

\section{III.STABILITY ANALYSIS}

Based on laboratory testing and field observation in the chromite mine, the material in the mine is identified as soil type. Generally circular failures in the benches are expected 
in soil type of material. Keeping this in view, strength reduction technique method was used for the slope stability

TABle I. Material Properties Of Different Lithology In The Mine [3]

\begin{tabular}{|c|c|c|c|}
\hline Lithology & $\begin{array}{c}\text { Bulk Density } \\
\left(\mathbf{k g} / \mathbf{m}^{\mathbf{3}}\right)\end{array}$ & $\begin{array}{c}\text { Cohesion } \\
(\mathbf{k P a})\end{array}$ & $\begin{array}{c}\text { Friction } \\
\text { Angle } \\
(\mathbf{D e g r e e})\end{array}$ \\
\hline North side section & 1800 & 28.54 & 30 \\
\hline Limonite material & 1770 & 28.54 & 30 \\
\hline Serpentinite material & & 24.00 & 32 \\
\hline South side section & 1930 & 24.00 & 32 \\
\hline Limonite material & 1770 & 28.00 & 30 \\
\hline Serpentinite material & & 28.00 & 30 \\
\hline Dump Material & 1670 &
\end{tabular}

analysis, considering a number of circular failure surfaces. The analysis was carried out using the software 'FLAC/SLOPE', developed by Itasca, USA [1]. In this, the factor of safety of potential failure surface is computed for different sections, and the critical failure surface (the surface having the least factor of safety) is identified.

The present pit slope (147 m depth) and the ultimate pit slope (up to $182 \mathrm{~m}$ depth) were designed considering the

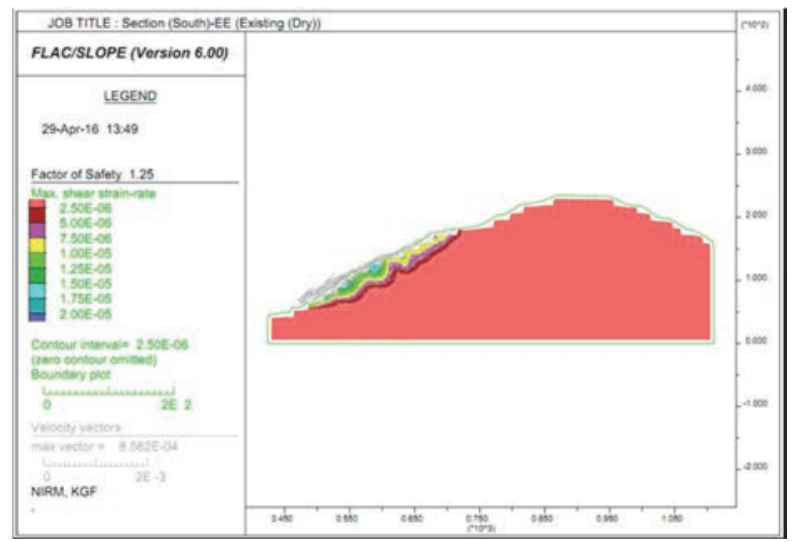

Fig. 3 Analysis of critical section (Present) on south side for dry condition.

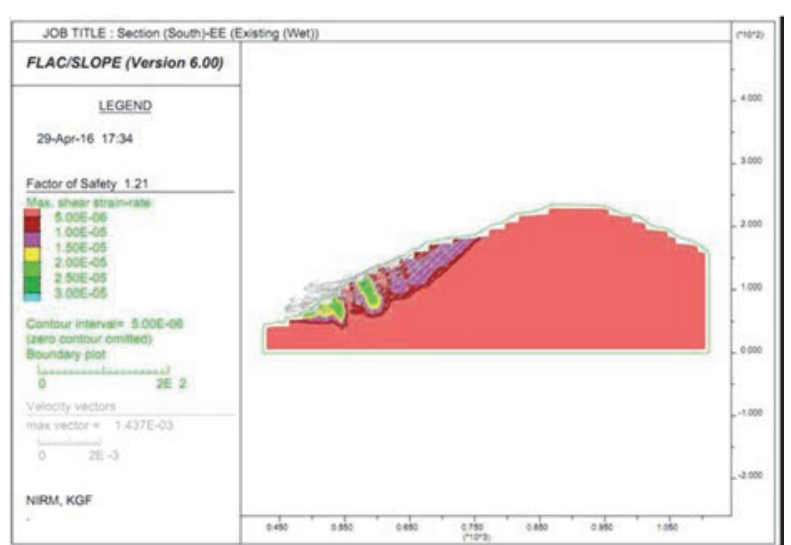

Fig. 4 Analysis of critical section (Present) on south side for fully saturated condition. following conditions based on the results of the geotechnical study:

a) The mode of failure for the slopes of this mine is categorized as a circular failure due to the presence of highly weathered lithological units in the hanging wall and footwall.

b) The average value from the range of peak shear strengths obtained after direct shear tests in the laboratory (Table 1) was used for slope design.

c) Stability analysis was performed for two conditions. Initially no water table was considered. Later, the water table was considered to be $105 \mathrm{~m}$ depth from surface.

d) A 1.3 factor of safety was selected for the pit slope to a depth of $182 \mathrm{~m}$ on the basis of the long term stability [2].

\section{A. Slope Design (South side)}

The present overall slope of critical section towards south side with a depth of $147 \mathrm{~m}$ is found to be stable with a overall slope angle of 280 under dry and fully saturated condition with a safety factor of 1.25 and 1.21 respectively, which are given in figures 3-4[3].

Analysis of projected overall slope of critical section towards south side with a depth of $182 \mathrm{~m}$ with reformed dump-3 is found to be stable with a overall angle of 260 under dry and fully saturated condition with a safety factor of 1.46 and 1.30 respectively, which are given in figures 5-6 [3].

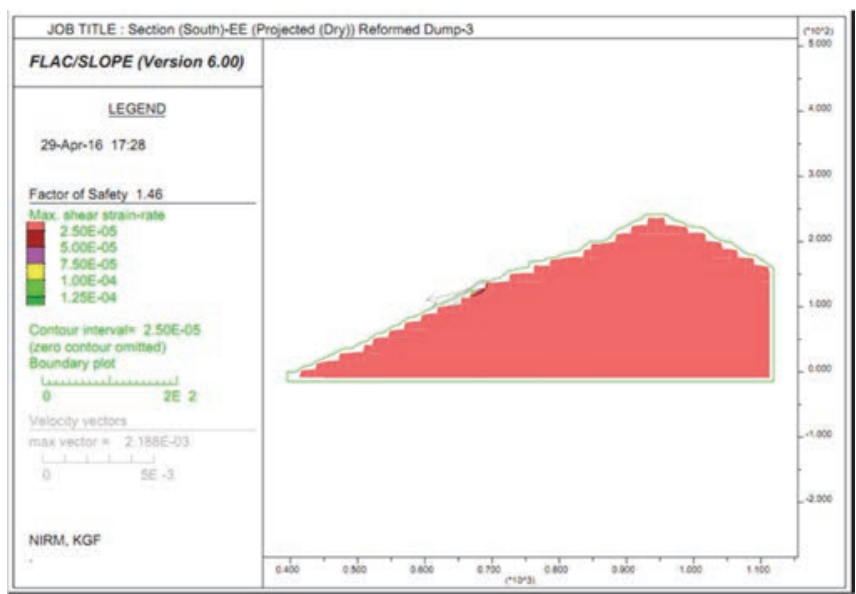

Fig. 5 Analysis of critical section (Projected) with reformed Dump-3 on south side for dry condition.

\section{B. Slope Design (North side)}

The present overall slope of critical section towards north side with a depth of $98 \mathrm{~m}$ is found to be stable with a overall slope angle of 19.50 under dry and fully saturated condition with a safety factor of 1.38 and 1.30 respectively, which are given in figures $7-8[3]$.

Analysis of projected overall slope of critical section towards north side with a depth of $140 \mathrm{~m}$ with reformed dump-2 is found to be stable with a overall angle of 25.50 under dry and fully saturated condition with a safety factor of 
1.37 and 1.30 respectively, which are given in figures $9-10$ [3].

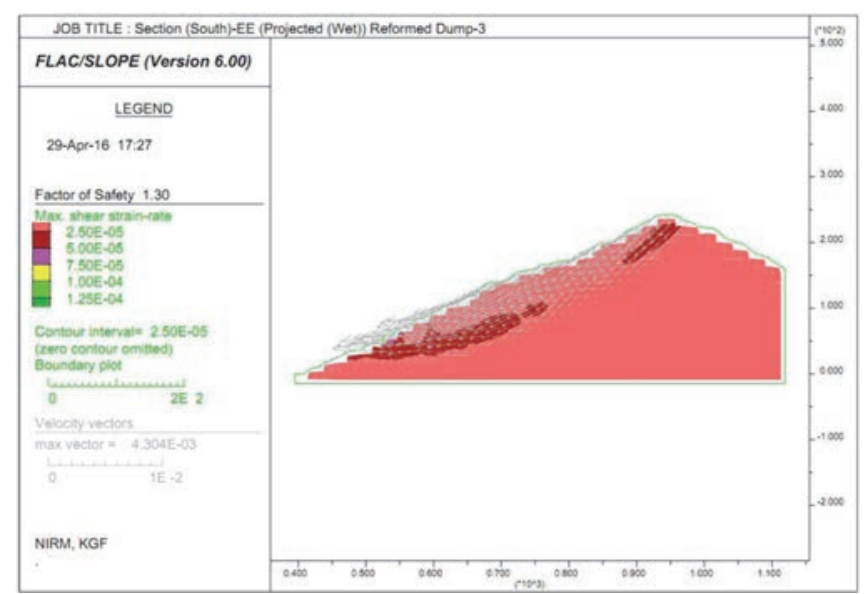

Fig. 6 Analysis of critical section (Projected) with reformed Dump-3 on south side for fully saturated condition.

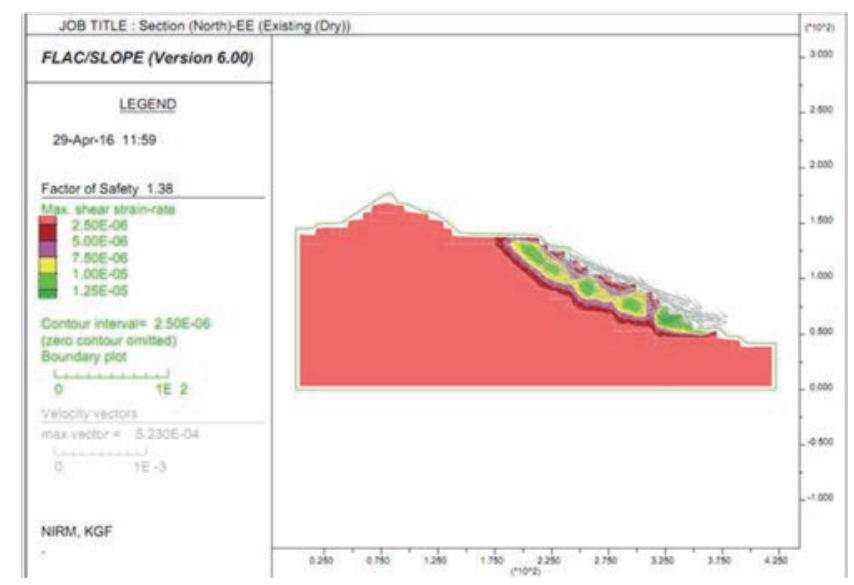

Fig. 7 Analysis of critical Section (Present) on north side for dry condition.

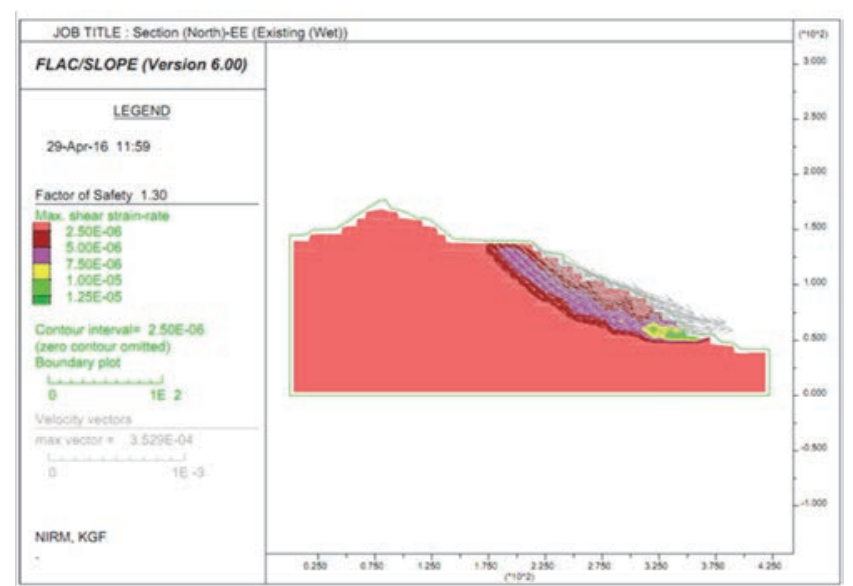

Fig. 8 Analysis of critical Section (Present) on north side for fully saturated Condition

The sensitivity analyses of the slope have been performed because of the possible differences in shear strength properties and ground-water conditions. The sensitivity analyses indicated that the influence of the friction angle is more than that of cohesion, and the influence of groundwater on the safety factor is significant. Good drainage has been provided on the benches to divert the surface rain water away from the pit. These drains are effectively maintained in the rainy season.

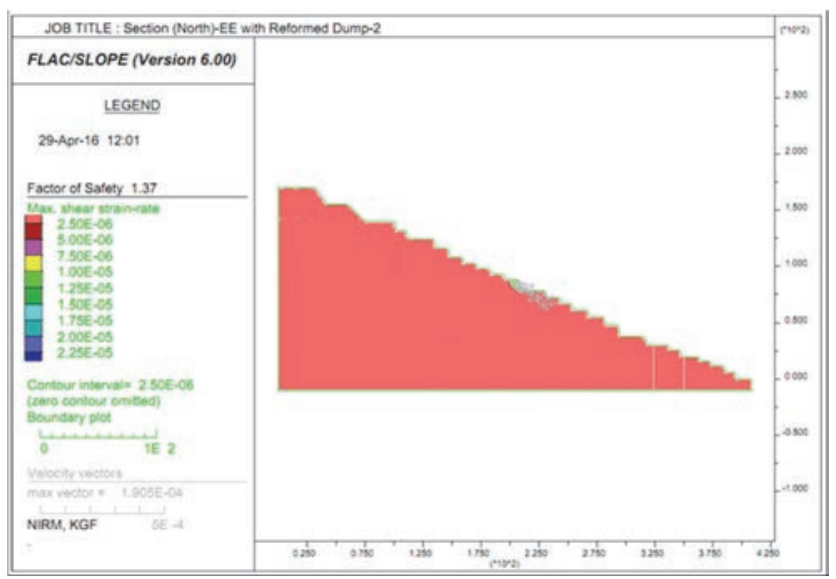

Fig. 9 Analysis of critical section (Projected) with reformed Dump-2 on north side for dry condition.

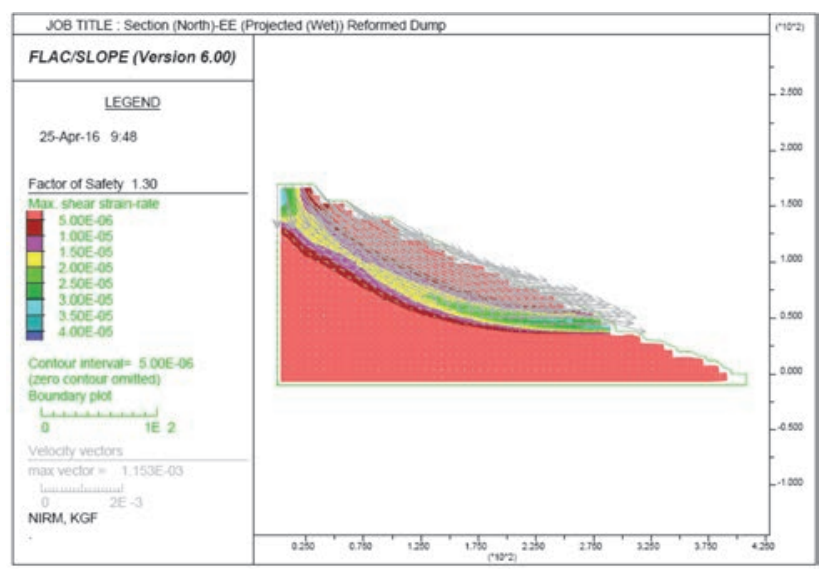

Fig. 10 Analysis of critical section (Projected) with reformed dump-2 on north side for fully saturated condition.

\section{IV.CONCLUSIONS}

The slope stability analysis with FLAC/Slope numerical method has found appropriate for the slope failure analysis. It can be used for similar geo-mining conditions of an open pit chromite mine.

The present open pit towards north and south directions were designed with an overall slope angle of 19.50 for a depth of $98 \mathrm{~m}$ and 280 for a depth of $147 \mathrm{~m}$ respectively. After geotechnical studies in open pit towards north and south directions were designed with an overall slope angle of 25.50 for a depth of $140 \mathrm{~m}$ and 260 for a depth of $182 \mathrm{~m}$ were recommended.

\section{ACKNOWLEDGEMENTS}

The authors are thankful to the mine management for providing all facilities, information and helpful discussion during the period of field study. The author is grateful to Director, NIRM for permitting to publish the paper in international conference. 


\section{REFERENCES}

[1] FLAC/SLOPE, " FLAC slope version 6 manual”. Itasca consulting group, Inc. USA, 2010.

[2] E. Hoek, and J.W. Bray, "Rock Slope Engineering", The Institution of Mining and Metallurgy, London, 1981.

[3] NRM Report, Report on "Slope stability studies at Kaliapani Chromite Mine, Kaliapani, Jajpur District, Odisha”, 2016. 